\title{
Study on the Minimum Safety Thickness of Goaf Overlying Strata based on UDEC in Baorixile Surface Coal Mine
}

\author{
Xing-Jun $\mathrm{JU}^{1, \text { a }}$, Tao SHANG ${ }^{2,3, \mathrm{~b}^{*}}$, Shu-Zhao $\mathrm{CHEN}^{2,3, \mathrm{~d}_{*}}$, Meng $\mathrm{YANG}^{2, \mathrm{e}}$ and \\ Wen-Bin $\mathrm{ZHU}^{2, \mathrm{f}}$
} ${ }^{1}$ Shenhua Baorixile Energy Industral Co., Itd, Hulun Buir, the Inner Mongolia Autonomous Region,
021000, China

${ }^{2}$ School of Mines, China Universities of Mining and Technology, Xuzhou, Jiangsu, 221116, China

${ }^{3}$ State Key Laboratory of Coal Resources and Safe Mining, China University of Mining and Technology, Xuzhou, Jiangsu, 221116, China

a11550076@shenhua.cc; bst54321@263.net; 'chshzh052@163.com;

d1203328760@qq.com; e884011840@qq.com

*Tao SHANG *Shu-Zhao CHEN

Keywords: Goaf; safety thickness; UDEC; surface coal mine

\begin{abstract}
The determination of safety thickness of overlying strata is the prerequisite for the treatment of mined out areas. Taking the mudstone of the Cenozoic Pleistocene as the upper bound of the model and the 1\# coal seam floor as the lower bound, the stress and strain of overlying strata under goaf span $15 \mathrm{~m} \sim 40 \mathrm{~m}$ was simulated based on the resources hosting condition at Baorixile Surface Coal Mine. By comparing the numerical simulation result with 8 theoretical methods the safety thickness of overlying strata is approximately parabolic with the increase of goaf span. The paper found out the relationship between the goaf span and the safety thickness of overlying strata with quadratic function regression analysis based on multiple methods, thus, evaluated the stability of 20 large goaf. The productive practice of surface coal mine has proved that it is reliable to treat the goaf based on the safety thickness of overlying strata.
\end{abstract}

\section{Introduction}

Goaf has become a threat in the production of surface coal mine, so it is of great importance to treat the goaf effectively in order to ensure production safety and improve the efficiency of resource development $[1,2]$. On the premise of accurate detection, determining the safety thickness of overlying strata is the basis for the stability evaluation and treatment selection of goaf [3]. Therefore, scholars at home and abroad have done a lot of research on this issue. At this stage, the research on safety thickness of overlying strata in goaf mainly includes 3 methods: Mechanics model theory analysis, similar material simulation method and numerical simulation method [4-10]. In order to overcome the shortcomings of different methods, many scholars have tried to adopt various methods to determine the minimum safe thickness of overlying strata in goaf $[11,12]$. For example, a theory was raised by Yan Enke that the minimum safety thickness of overlying strata in goaf can be determined by thickness span ratio method, Pry pressure arch method, Lupe Neut theory and 3-d numerical simulation[13]; Wang Ruixue calculated the results with ANSYS numerical simulation method and five classical methods of theoretical calculation including thickness span ratio method, intersection method of load transfer line, theoretical calculation method of structural mechanics beam, the estimation method of the Pry arch theory and K.B. Lupe Neu theory estimation method respectively, finding out that the result variation trends calculated are basically the same[14]; Fei Pengcheng studied the safety thickness of overlying strata in goaf under the condition of open-underground combined mining with theoretical calculation and ANSYS numerical simulation [15]. In order to know the safety thickness of the overlying strata in different goaf of Baorixile Surface Coal Mine accurately, the paper combined a variety of theoretical methods to study the 
relationship between the goaf span and the safety thickness of overlying strata based on the software simulation of UDEC.

\section{Analysis of Goaf Occurrence}

The depth of main coal seam is $70-99 \mathrm{~m}$; the roof of coal seam is mainly siltstone, mudstone and medium coarse sandstone, which belongs to soft rock with low diagenesis. Due to historical reasons, a lot of goaf has been formed near the southern part of the Baorixile Surface Coal Mine (Fig. 1), and some of them have collapsed. In order to find out the goaf distribution, the CAS, China University of Mining and Technology, the Northeast survey team, the China University of Mining and Technology science and Technology Development Corporation, the Beijing Geotechnical Engineering Survey Institute and other units have been commissioned successively to survey the goaf occurrence in this area. The main drilling works arranged and the goaf distribution is demonstrated in Fig. 2.

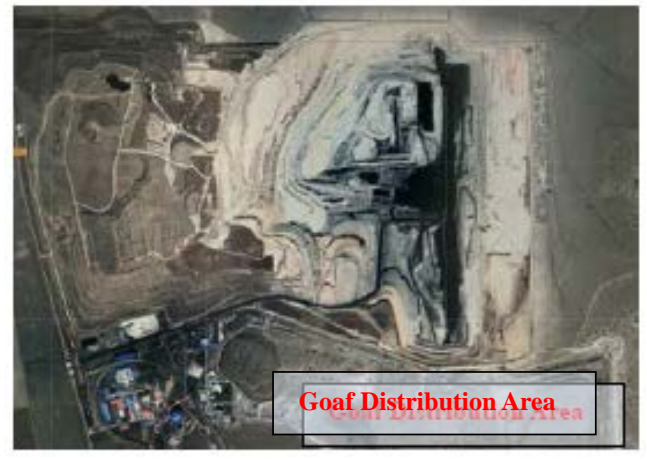

Fig. 1 Goaf Distribution Area

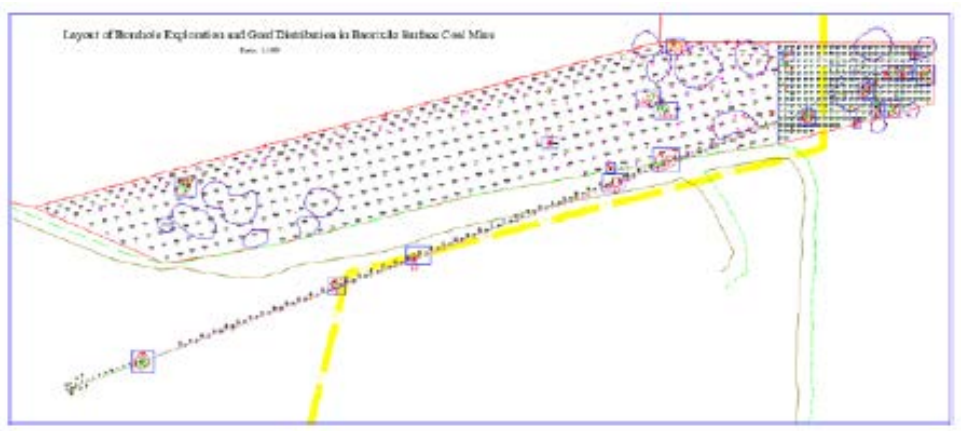

Fig. 2 The distribution of drilling works and goaf

\section{Modeling of Goaf based on UDEC}

UDEC is a program that use discrete element to simulate the deformation, failure or movement of rock mass when the discontinuous medium under the action of static pressure or dynamic pressure. The overlying rock in the goaf is no longer continuous and whole, so UDEC is used as modeling software.

\section{Numerical Model Range}

The underground goaf will cause the stress change of the original rock mass, resulting in deformation, movement and even destruction until the new stress balance is reached. The open-cast mining will break the newly established stress balance, which leads to the new deformation and movement of the roof and the floor. It will enlarge the influence scope of the goaf, even threaten the safety of the work and equipment. Taking the mudstone of the Cenozoic Pleistocene as the upper bound of the model and the 1\# coal seam floor as the lower bound based on the resources hosting condition and mining equipment at Baorixile Surface Coal Mine. The model is shown in Fig. 3. 


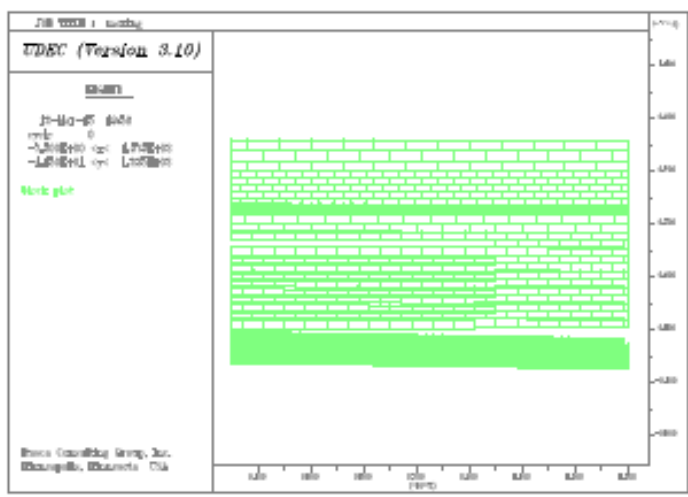

Fig. 3 Numerical model

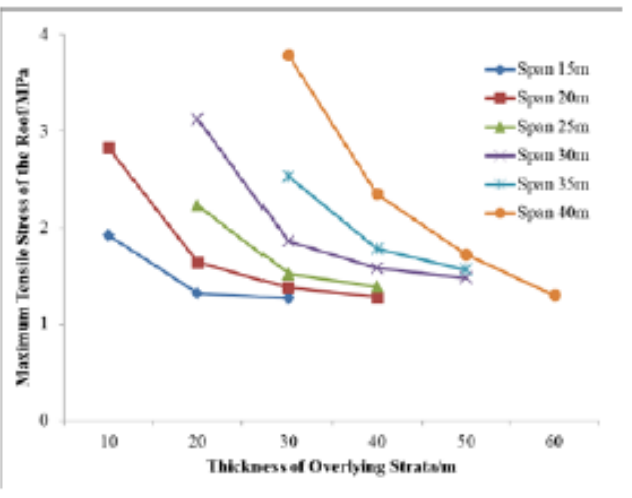

Fig. 4 Maximum stress curve

\section{Boundary Conditions and the Selection of Initial Stress Field}

According to the production conditions of surface coal mine, the following assumptions are made to the model boundary and the initial stress field:

(1) The lower boundary of the model is simplified as the fixed boundary condition, which means the displacement of the lower boundary in horizontal and vertical directions is restricted. Therefore, $\mathrm{u}=\mathrm{v}=0$.

(2) The left and right boundary of the model is simplified as the displacement boundary condition, which means only the displacement in the vertical direction is restricted. Therefore, $\mathrm{u}=0$.

(3) The upper boundary of the model is simplified as a free boundary condition; the equipment above the boundary is added to the upper boundary of the model through loading. The paper used the pressure that the biggest equipment applied to the ground. The pressure that MT4400 Self-Discharge Tramcar applies to the ground when it is fully loaded is $\sigma$ yy $=0.56 \mathrm{MPa}$.

(4) Horizontal stress depends on vertical stress and side pressure coefficient and the side pressure coefficient is related to factors like buried depth and lithology. In order to achieve the purpose of accurate simulation, the side pressure coefficient was determined according to relevant data:

$$
\lambda_{c}=\frac{140}{H}+0.78
$$

\section{Determination of Rock Mechanics Parameters}

By proper simplification of the synthesis column map, the coal and rock strata of the model are determined from top to bottom are: mudstone, siltstone, fine sandstone, moderate coarse sandstone and $1 \#$ coal seam. The physical and mechanical parameters of each stratum are shown in Table 1.

Table 1 Rock mechanical parameters table

\begin{tabular}{|c|c|c|c|c|c|c|}
\hline No. & Name & Mudstone & Siltstone & $\begin{array}{c}\text { Fine } \\
\text { sandstone }\end{array}$ & $\begin{array}{c}\text { Moderate } \\
\text { coarse } \\
\text { sandstone }\end{array}$ & $\begin{array}{c}\text { 1\# coal } \\
\text { seam }\end{array}$ \\
\hline 1 & Moisture content (\%) & 20.9 & 17.6 & 18.7 & 20.2 & 25.46 \\
\hline 2 & Compressive strength(MPa) & 3.56 & 2.59 & 1.93 & 1.78 & 1.15 \\
\hline 3 & Tensile strength(MPa) & 1.92 & 1.43 & 1.90 & 2.13 & 0.57 \\
\hline 4 & Elastic modulus(Gpa) & 15.32 & 32.60 & 29.63 & 28.32 & 4.32 \\
\hline 5 & Poisson ratio & 0.42 & 0.45 & 0.44 & 0.45 & 0.18 \\
\hline 6 & Bulk density(g/cm $\left.{ }^{3}\right)$ & 1.91 & 1.90 & 1.91 & 1.90 & 1.14 \\
\hline 7 & Cohesion(MPa) & 0.63 & 0.46 & 0.38 & 0.20 & 0.90 \\
\hline 8 & Softening coefficient $(\%)$ & 0.41 & 0.39 & 0.28 & 0.21 & 0.58 \\
\hline 9 & Internal friction angle $\left({ }^{\circ}\right)$ & 22.9 & 22.9 & 22.8 & 29.0 & 34.8 \\
\hline
\end{tabular}




\section{The Yield Criterion of the Model}

The Moore Kulun criterion is used in the model and the surface contact slip model is used as ubiquitous - joint model. The yield conditions are as follows:

$$
\begin{aligned}
f_{s}=\sigma_{1}-\sigma_{3} N_{\phi}+2 c \sqrt{N_{\phi}} \\
\text { With: } \quad N_{\phi}=(1+\sin \phi) /(1+\sin \phi)
\end{aligned}
$$

Where is: $\sigma_{1}$-Maximum principal stress; $\sigma_{3}$-Minimum principal stress; $\varphi$-Internal friction angle; $c$-Cohesion.

If $f_{s}<0$, then shear yielding happens, otherwise if $f_{s} \geq 0$, tension yielding happens.

\section{Analysis of Numerical Simulation Results}

With regard to the roof rock in the goaf, the main reason for its failure is that the tensile stress reaches the allowable tensile stress of the rock, the tensile fracture is expanded and contacts with the surface, leading to shear failure. Therefore, the paper determines the minimum safe thickness of overlying strata in goaf by analyzing the maximum tensile stress of roof strata in goaf. The basic idea of this paper is to give a relatively large thickness of the overlying strata in the goaf based on the stratigraphic model. Then the thickness of the overlying strata is reduced by gradual excavation. When the tensile stress of the roof strata in goaf reaches the allowable tensile stress of rock, the thickness of overlying strata is the minimum safety thickness.

According to the mining conditions at Baorixile Surface Coal Mine, excavation simulation was carried out for goaf with the span of $15 \mathrm{~m}, 20 \mathrm{~m}, 25 \mathrm{~m}, 30 \mathrm{~m}, 35 \mathrm{~m}$ and $40 \mathrm{~m}$ respectively. The influence of overlying strata is shown in Figure 4. Take the example of span $30 \mathrm{~m}$, which was most representative, the maximum tensile stress distribution of $50 \mathrm{~m}$ and $30 \mathrm{~m}$ is shown in Figure 5.

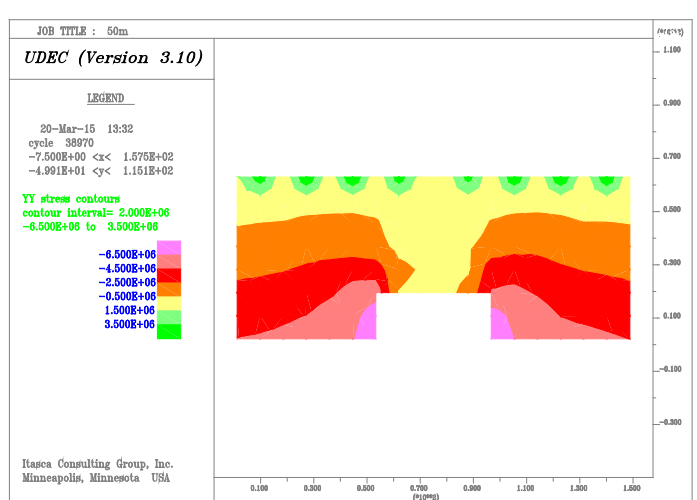

(a) Thickness $50 \mathrm{~m}$

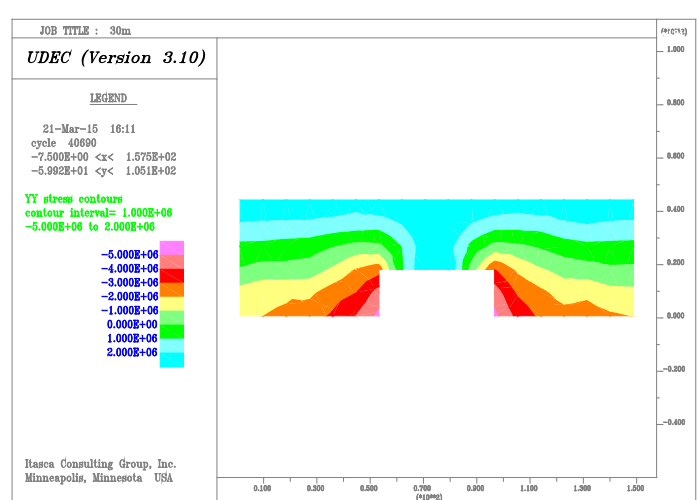

(b) Thickness 30m

Fig. 5 Tensile stress distribution at different thickness upon goaf span 30m

\section{The Safety Thickness of Overlying Strata in Goaf}

In order to keep the safety of regular production and work of surface coal mines, a certain safety thickness should be reserved for the overlying strata in goaf. If the thickness is too small, it may cause the upper bench in goaf to collapse, which will do harm to people and equipment. The safety thickness of overlying strata in goaf is affected by many factors, including geological factors and mechanical properties of rock, goaf characteristics, and exterior activities and so on. According to the results of the data simulation, the relationship between the minimum safety thickness and the span of goaf at Baorixile Surface Coal Mine is analyzed in Table 2. 
Table 2 Relationship between the minimum safety thickness and the span of goaf (m)

\begin{tabular}{|c|c|c|c|c|c|c|c|c|}
\hline & \multirow{2}{*}{ Methods } & \multirow{2}{*}{ No. } & \multicolumn{6}{|c|}{ span of goaf } \\
\hline & & & 15 & 20 & 25 & 30 & 35 & 40 \\
\hline \multicolumn{2}{|c|}{ Numerical simulation } & 1 & 12.14 & 17.45 & 23.50 & 30.35 & 38.03 & 46.61 \\
\hline \multirow{8}{*}{$\begin{array}{l}\text { Theoretical } \\
\text { calculation }\end{array}$} & $\begin{array}{c}\text { Thickness span ratio } \\
\text { method }\end{array}$ & 2 & 9.75 & 13.00 & 16.25 & 19.50 & 22.75 & 26.00 \\
\hline & $\begin{array}{l}\text { Intersection method of } \\
\text { load transfer line }\end{array}$ & 3 & 10.71 & 14.28 & 17.85 & 21.42 & 24.99 & 28.56 \\
\hline & Pry arch theory & 4 & 12.20 & 16.26 & 20.33 & 24.39 & 28.46 & 32.52 \\
\hline & Structural beam theory & 5 & 7.75 & 10.80 & 14.10 & 17.68 & 21.53 & 25.67 \\
\hline & Pogorupov method & 6 & 4.77 & 7.13 & 10.17 & 13.89 & 18.28 & 23.35 \\
\hline & Plate beam theory & 7 & 4.57 & 8.13 & 12.70 & 18.28 & 24.89 & 32.50 \\
\hline & $\begin{array}{c}\text { Small deformation thin } \\
\text { plate theory }\end{array}$ & 8 & 12.75 & 15.99 & 19.15 & 22.50 & 26.25 & 30.80 \\
\hline & Rupene Bea Te theory & 9 & 15.73 & 26.43 & 39.88 & 56.08 & 75.04 & 96.74 \\
\hline
\end{tabular}

Since the rock stratum is an inhomogeneous medium, the safety thickness can be calculated by thickness span ratio method and Pry arch theory. According to the occurrence characteristics of goaf and overlying strata at Baorixile Surface Coal Mine, the minimum safe thickness calculated by theoretical method is shown in Table 2.

Comparing the data in Table 2, the result calculated by Rupene Bea Te theory is larger than others obviously. The main reason is that the method takes the highest uniaxial compression strength as parameter, which is usually applied in metal and nonmetal mines with high rock hardness [16, 17]. Therefore, the result is respectively large at Baorixile Surface Coal Mine that mines lignite with low intensity. The results of the calculation and numerical simulation are shown in Figure 6.

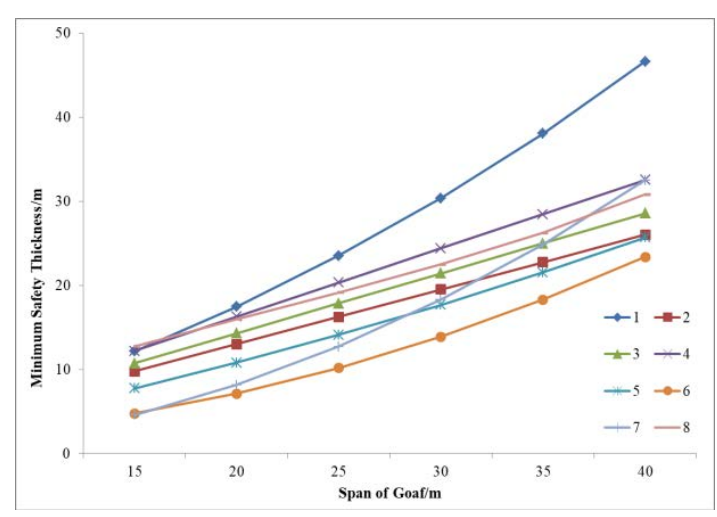

Fig. 6 minimum safety thickness of overlying strata

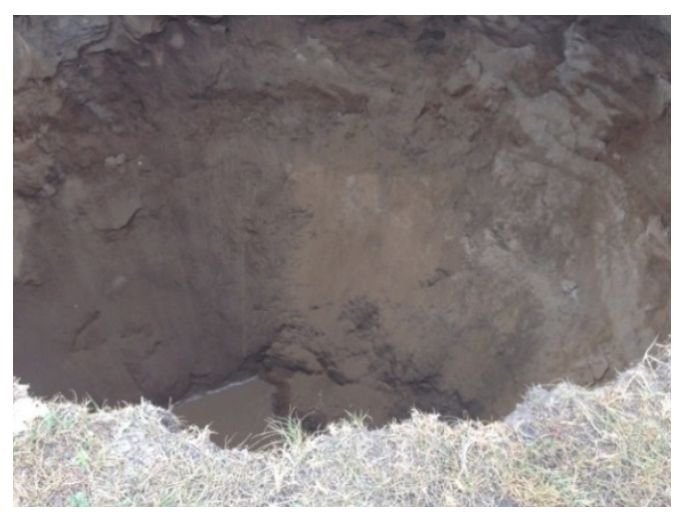

Fig. 7 11\# Collapsed area

By comparing the results, the minimum safety thickness of overlying strata calculated by various methods are close when the goaf span is small. The safety thickness of overlying strata is approximately parabolic with the increase of goaf span. Considering the characteristics of each method and emergency capacity, the relationship between the minimum safety thickness and the goaf span is obtained by quadratic function as follows:

$$
h=0.02 L_{n}^{2}+0.51 L_{n}+1.43
$$

After checking, the error of the fitting formula can satisfy the calculation requirement, so it can be used as the formula for calculating the minimum safety thickness of the overlying strata in Baorixile Surface Coal Mine. 


\section{Stability Evaluation of Goaf}

There are 20 goafs at Baorixile Surface Coal Mine confirmed by drilling. There are 12 stable goafs, 6 unstable goafs and 2 goafs with poor stability. For stable goaf, it is safe for transportation on its surface, but should be treated in time in order to avoid geological disasters in the later stage. For unstable goaf, it should be treated at once and pay special attention to the safety of operation. For example, casing pipe failure and goaf collapse happened during the grouting filling treatment in 11\# goaf confirmed by Hole K-18 (shown in Fig. 7). Fortunately, corresponding safety measures were taken to avoid accidents. For the goaf with poor stability, warning lines should be set up and the goaf should be treated in time.

\section{Conclusion}

The paper studied the safety thickness of overlying strata in goaf based on the characteristics of the goaf occurrence near the southern end slope of the Baorixile Surface Coal Mine. Conclusions are as follows:

(1) The paper used UDEC as simulation software based on the fracture characteristics of overlying strata in goaf. It is reasonable to make the maximum tensile stress of roof strata larger than the tensile strength of rock as criteria for rock failure.

(2) The minimum safety thickness calculated by UDEC is larger than those calculated by others except K.B.Rupene Bea Te theory.

(3) The practice of Baorixile Surface Coal Mine proved that it is reasonable to take the formula for calculating the minimum safety thickness of overlying strata by regression analysis as criteria for stability evaluation of goaf.

\section{Acknowledgments}

Thanks to the financial support of National Key Research and Development Program of China (2016YFC0501103).

\section{Reference}

[1] MIAO Yue, WU Mao, ZHAO Tianyou. Effect and countermeasures of goaf on open-pit mining [J]. Opencast Mining Technology, 2018, 33(3): 21-25.

[2] WANG Haijun. Study on Development Mode and Key Open Pit Mining Technology in Integration Resources Mine [D]. Xuzhou: China University of Mining and Technology, 2014.

[3] DING Xinpin, LI Wei, WU Mao, etc. Risk Assessment Method and Practice for Underground Gob Area in Open pit mine [J]. Safety in Coal Mines, 2015, 46(2): 217-220.

[4] Bauer E R, Chekan G J, Steiner L J. Stability evaluation of ex-tended cut mining in underground coal mines [J]. International Journal of Rock Mechanics and Mining Sciences \& Geomechanics Abstracts, 1997, 34 (3): 664-668.

[5] ZHEN Yunjun, CHEN Kaixiang, LIU Yingfa, etc. Determination of roof safety thickness for underground mined-out area [J]. Industrial Minerals \& Processing, 2007, 09: 19-20+36.

[6] LI Diyuan, LI Xibing, ZHAO Guoyan. Roof Security Thickness Determination of Underground Goaf Under Open - pit Mine [J]. Opencast Mining Technology, 2005, (5): 21-24.

[7] YAN Xiaoming, LI Xibing, LI Diyuan, etc. Determination of Boundary Pillar's Safety Thickness of Open Pit Mining with Underground Goaf[J]. Chinese Journal of Underground Space and Engineering, 2006, 2(4): 666-671.

[8] LIN Hang, CAO Ping, LI Jiangteng, etc. The Thickness Reduction Method in Forecasting the 
Critical Safety Roof Thickness of Gob Area [J]. Journal of China Coal Society, 2009, 34(1): 53-57.

[9] LIU Xiaobo, PENG Jianyu. Goaf Roof Failure Mechanism and its Security Thickness [J]. Metal Mine, 2012, (11): 5-8+13.

[10] LIU Weidong. The Study on the Safe Thickness of Top Plate of Goaf and Processing Method From Underground Mining to Open Pit [D]. Beijing: North China University of Technology, 2016.

[11] ZHU Fangcai, CAO Ping, WAN Wen. Determination of Safe Roof Thickness of Underground Shallow Openings Based on Ax symmetric Thick Plate Model [J]. Journal of Mining\& Safety Engineering, 2006, 23(1): 115-118.

[12] WANG Shuren, JIA Huihui, WU Chongfu. Determination method of roof safety thickness in the mined-out regions under dynamic loading and its application [J]. Journal of China Coal Society, 2010, 35(8): 1263-1268.

[13] YAN Enke, YAO Guodong, WAN Zhongming. Study of the minimum safety thickness of the underground goaf in surface mine [J]. Industrial Minerals \& Processing, 2011, (5): 23-25.

[14] WANG Ruixue. Study on the Safety Thickness of Disused Laneway Roof in Wujiata Surface Mine[D]. Fuxin: Liaoning Technology University, 2012.

[15] FU Pengcheng, SONG Ziling, WANG Dong, etc. Research on the Reasonable Thickness of Cover Layer at Goaf under Condition of Open-underground Combined Mining based on Ansys [J]. Modern Mining, 2012, (1): 8-10+17.

[16] QIN Yuhui, ZHU Xubo, LI Diyuan. Calculation of Safe Roof Thickness of Mined - out Area Under Open pit Based on K. B. Lu Peinie Theory [J]. Mining Research and Development, 2010, 30(4): 66-69.

[17] ZHANG Minsi, ZHU Wancheng, HOU Zhaosong, etc. Numerical Simulation for Determining the Safe Roof Thickness and Critical Goaf Span [J]. Journal of Mining\& Safety Engineering, 2012, 29(4): 543-548. 